\title{
Educação inclusiva: contribuições para o desenvolvimento de um compromisso ético em sua efetivação*
}

\section{Inclusive education: contributions to the development of an ethical commitment in its implementation}

\author{
Aline Cristina Barroso Silva ${ }^{1}$
}

\begin{abstract}
SILVA, A. C. B. Educação inclusiva: contribuições para o desenvolvimento de um compromisso ético em sua efetivação. Rev Ter. Ocup. Univ. São Paulo, v. 23, n. 2, p. 163-168, maio/ago. 2012.

RESUMO: Pretende-se contribuir com as reflexões a respeito do cotidiano escolar, em contextos de educação regular nos quais haja a participação de crianças que apresentem comprometimentos motores, associados ou não a outras dificuldades. Abordando-se, inicialmente, a inclusão escolar e a prática da Terapia Ocupacional no contexto da Educação Infantil, visa-se, em segundo momento, uma análise de pensamentos e ações dos profissionais envolvidos com a inclusão, enfatizando-se o compromisso ético nas relações e no desenvolvimento de um trabalho que se volte ao "desprendimento" da condição de deficiência, à valorização das possibilidades da criança, à superação de preconceitos e superstições e à garantia de que os processos de ensino e aprendizagem ocorram de modo significativo.
\end{abstract}

DESCRITORES: Educação infantil; Terapia ocupacional; Atividades cotidianas/psicologia; Educação de pessoa com deficiência intelectual; Educação; Criança; Aprendizagem.

\footnotetext{
* Trabalho realizado a partir da monografia apresentada para obtenção do grau de Especialista no Curso Terapia Ocupacional em Reabilitação, Recursos Tecnológicos e Inclusão Social da Pessoa com Deficiência, do Departamento de Fisioterapia, Fonoaudiologia e Terapia Ocupacional da Faculdade de Medicina da Universidade de São Paulo.

1. Terapeuta Ocupacional da Equipe de Orientação Técnica da Secretaria de Educação da Prefeitura de São Bernardo do Campo, SP. Endereço para correspondência: Rua Duque D’Abruzzo, 262, Rudge Ramos, S.B. do Campo - CEP: 09621-000. e-mail: alinecbsilva@ yahoo.com.br
} 


\section{INTRODUÇÃO}

partir da reflexão sobre o cotidiano escolar
no contexto da educação regular, onde há
a participação de crianças que apresentam comprometimentos motores, associados ou não a outras deficiências, propõe-se, aqui, um debate sobre esta temática, realizado a partir de um trabalho de campo em escolas de Educação Infantil do município de São Bernardo do Campo. Ressalta-se a importância da responsabilidade no direcionamento de intervenções que favoreçam a efetiva participação das crianças, desatando-se os nós que historicamente amarraram ao próprio indivíduo e a sua condição de deficiência as impossibilidades na aprendizagem.

Parte-se, inicialmente, de considerações referentes à inclusão escolar e da apresentação de um olhar sobre o papel do terapeuta ocupacional. Em seguida, na tentativa de se enfatizar o compromisso ético nas relações e no desenvolvimento de um trabalho que se volte à promoção de um "crescimento" de cada "ator" envolvido neste desafiador movimento de inclusão, propõe-se uma análise dos pensamentos e ações constituintes deste processo.

$\mathrm{Na}$ intenção de valorizar o cotidiano na Educação, o material de análise para este debate é referente ao registro diário de observações, intervenções e reflexões possibilitadas no acompanhamento escolar, que tem como características relevantes do trabalho a maior aproximação às equipes gestoras e ao histórico do processo de participação relacionado a cada criança; as observações em contexto e o acompanhamento ao trabalho do professor; a maior compreensão das propostas e das relações que se estabelecem, bem como das dificuldades e possibilidades encontradas; as orientações referentes a adaptações que visem contribuir com a participação da criança, considerando-se não somente suas singularidades, mas o compromisso de um trabalho pensado também a partir de seu grupo e das propostas que a ele se voltem, na garantia da participação de cada membro.

As solicitações para a intervenção do terapeuta ocupacional neste município se faz a partir de demandas relacionadas principalmente a situações de inclusão de crianças com deficiências físicas. O período estabelecido para a obtenção de dados foi referente ao ano de 2006, durante os meses de março a dezembro, sendo que, das vinte e oito escolas percorridas, dez foram selecionadas pela identificação de conteúdos que possibilitassem articulações com referenciais teóricos e reflexões sobre os desafios da inclusão. Os registros de campo foram norteados pela atenção aos seguintes aspectos: maior entendimento dos ambientes que constituem a Educação Infantil e das rotinas elaboradas; planejamento de atividades e posturas dos diferentes profissionais; identificação de necessidades, solicitações e dificuldades; intervenções desencadeadas e reflexões possibilitadas diante da inclusão de crianças com deficiência neste contexto escolar.

Os procedimentos éticos de pesquisa foram garantidos. Para a utilização dos registros foi solicitada autorização ao Departamento de Ações Educacionais da Secretaria de Educação e Cultura da Prefeitura do Município de São Bernardo do Campo, Estado de São Paulo. No que se refere a situações específicas, ligadas aos diferentes participantes, foi utilizado Termo de Consentimento Livre e Esclarecido. Os nomes de profissionais, unidades escolares, crianças e familiares foram mantidos em sigilo, sendo fictícios os que aparecem no texto. Embora os relatos se dirijam a situações específicas, foram escolhidos por retratarem conflitos não exclusivos de uma única unidade ou vivenciados por conjunto único de pessoas, mas pela possibilidade de apresentarem aspectos que podem ser estendidos aos demais contextos da Educação. A intenção, assim, foi a de pensar como o processo de inclusão escolar ocorre e de contribuir com reflexões que possam ampliar as possibilidades reais de uma escola que de fato se volte à participação de todos.

\section{A INCLUSÃO ESCOLAR}

O cenário educacional passa por transformações que buscam superar o conceito de integração social, pelo qual a criança com deficiência deve ser preparada para a escolarização. No desenvolvimento da proposta de inclusão, a escola é colocada como participante responsável na promoção de um contexto inclusivo, devendo estar apta a receber todos os alunos. Neste caminho, propõe-se a revisão de conceitos como produção, capacidade, eficácia, normalidade, favorecendo a diversidade como possibilidade e encontrando soluções no coletivo, no ambiente e nos recursos disponibilizados ou criados (ROCHA et al., 2001).

No acompanhamento destas transformações, a legislação brasileira atual enfatiza a necessidade do oferecimento de serviços adequados. Há, por exemplo, um direcionamento para que as unidades escolares não sigam modelos padronizados, podendo ser orientadas por normas e referências mais gerais e aderindo a projetos pedagógicos próprios (FERREIRA; FERREIRA apud GÓES; LAPLANE, 2004).

Sem consideração a este processo, existe o perigo de se efetivar uma inclusão ilusória ou perversa, destituída do que Sawaia (1999) aponta como imprescindível 
nas reflexões sobre exclusão: a ideia de humanidade; a valorização do sujeito, de seus desejos e afetos; a consideração com a maneira como ele se relaciona com o social; o questionamento do sofrimento, que se reflete diretamente no cotidiano, na capacidade de autonomia e na subjetividade.

Nas práticas cotidianas das escolas, muitas situações denunciam, ainda que não intencionalmente, o lado perverso da inclusão. É comum nos depararmos com situações nas quais o grupo de alunos acompanha as explicações sobre determinada atividade, enquanto uma criança com limitações físicas e sensoriais, separada do grupo, desenvolve proposta individual. Pode-se dizer que tais situações ocorrem a partir da angústia diante do desafio da inclusão, da sensação de impotência diante de uma criança que não responde como convencionalmente se espera e do despreparo do professor. Existem ainda as dificuldades encontradas nas próprias condições estruturais e de oferecimento de recursos, o que contribui para se compreender o quanto este movimento pode ser perverso também para o educador.

Busca-se, desta forma, "caminhos" que não se estagnem na produção discursiva e que possam, para além dela, efetivar a inclusão, ressaltando-se aqui os aspectos éticos e subjetivos que permeiam as diferentes histórias e vivências escolares que, quando relacionadas a situações que configuram a exclusão, podem denotar o descompromisso com o sofrimento do outro.

\section{A TERAPIA OCUPACIONAL E A EDUCAÇÃO INFANTIL}

\section{Contextualizando a prática}

O Terapeuta Ocupacional compõe o quadro de profissionais que têm agora a possibilidade de contribuir para o processo de escolarização, através de conhecimentos específicos referentes às diferentes necessidades e de maneira articulada com as responsabilidades pedagógicas. Delineando-se em torno do entendimento da importância de que as propostas sejam pensadas para o grupo, com respeito às individualidades e valorização das possibilidades de cada um, as intervenções visam transformar relações movidas muitas vezes por medos e preconceitos e contribuir para a superação das dificuldades e para a garantia ao aluno do acesso à informação que lhe é oferecida, bem como para a ampliação de sua participação.

A Educação Infantil pode ser vista como o primeiro ambiente fora do contexto familiar, no qual a criança amplia sua participação social, tendo contato com novas regras e novos conhecimentos. Identificando-se a responsabilidade dos profissionais envolvidos com esta prática, inclusive na orientação às equipes escolares, propõe-se um "olhar" para algumas situações das rotinas educacionais. Não se pretende aqui descrever as intervenções e seus desdobramentos, mas levantar reflexões que contribuam para se pensar "caminhos" na efetivação da inclusão. Foca-se, assim, a atenção em três eixos, necessariamente vinculados e atravessados um pelo outro, e considerados como mais recorrentes nas observações possibilitadas: a deficiência propriamente dita; os recursos tecnológicos e materiais adaptados; e os objetivos nas propostas. O texto é permeado por trechos dos registros de observação.

\section{Para além do corpo físico}

$\mathrm{Na}$ inclusão direcionada a crianças com dificuldades neuromotoras é importante referir os medos, preconceitos e dificuldades despertadas no contato direto com a deficiência expressa no corpo da criança em suas condições de espasticidade, de hipotonia, de reflexos, de alterações de tônus, dentre outras características. Nossa intervenção se faz em função da visão que se direciona a este "corpo". Se o vemos a partir do déficit, as orientações aos profissionais das escolas se pautarão pela tendência à adaptação motora e ao foco nas capacidades de reajuste que a criança com deficiência pode apresentar.

No momento de parque, a professora contou ter encontrado uma forma de estimular as aquisições motoras de Isabel: colocava determinado brinquedo a certa distância, de maneira que Isabel tinha que buscá-lo. Quando ela o fazia, a professora novamente tomava o brinquedo e o colocava mais à frente. Novamente Isabel o buscava.

O que se desconsidera, quando se busca prioritariamente o estímulo às conquistas motoras? Por que o investimento nas explorações dos brinquedos e na troca de experiências significativas com os colegas de grupo fica menos importante diante da presença de dificuldades físicas?

\section{O foco nos equipamentos e materiais adaptados}

Na busca dos significados referentes à utilização de um recurso adaptado, é importante que se aponte para os perigos de dois "extremos": a estrita localização da solução das dificuldades nesta utilização e a consequente justificativa das impossibilidades pedagógicas por esta falta unicamente; e, por outro lado, o negligenciamento a qualquer adaptação, sob o ponto de vista de se proporcionar ao aluno a não 
dependência a algo que no ambiente escolar teria um caráter extremamente contextualizado. Como ilustração, as palavras de um aluno podem fornecer a dimensão da importância de um cuidado no oferecimento ou não de um auxílio ou recurso:

Tendo percorrido andando, com auxílio de um andador e da professora, o corredor que levava ao momento do lanche (situação comum a todos os dias, pelo desejo da professora em estimular a conquista motora do aluno ), Marcelo dirigiu-se a mim dizendo: "tia, pede pra professora, eu quero vir com a cadeira de rodas...se eu venho andando, quando eu chego meus amigos já terminaram o lanche..."

É fundamental a valorização das escolhas do aluno e a efetivação de orientações contextualizadas ao ambiente escolar e às necessidades da criança, tanto em seus aspectos particulares, como na relação com o grupo.

\section{Repensando objetivos} relato:

Propõe-se aqui uma reflexão a partir do seguinte

$\mathrm{Na}$ atividade oferecida, as crianças recortavam versos, ordenando-os segundo a memorização de uma canção previamente apresentada ao grupo. Percebendo que Luciana não conseguia recortar nos limites destinados a cada verso, a professora passou a permitir que ela recortasse a seu modo, rasgando as frases. Em seguida, recolhia esse material, fazia outro para Luciana e colocava em seu registro.

Preocupada em não frustrar Luciana e em proporcionar sua participação, a professora talvez não estivesse conseguindo perceber aspectos importantes daquela vivência. O que a criança entendia como mensagem quando o material que por minutos e minutos ficava recortando era recolhido? Qual o real objetivo da proposta? O recorte em espaços limites para aquela atividade era necessário? Se necessário, para Luciana não seria importante que o espaço entre os versos fossem maiores? São questionamentos que remetem à importância de se reavaliar os objetivos das propostas, sua realização e o sentido das adaptações.

\section{DESDOBRANDO AS INTERVENÇÕES - ANÁLISE DE PENSAMENTOS E AÇÕES}

Em nossas intervenções como terapeutas ocupacionais, despertar os conflitos e mobilizar o encontro com soluções tornam-se os maiores desafios. Para tanto, a estratégia, em muitas situações, é partir da necessidade objetiva para a qual somos solicitados pela escola: o posicionamento adequado, a prescrição do mobiliário, a adaptação de materiais e utensílios, as transferências posturais, o auxílio para a comunicação, a eliminação das barreiras arquitetônicas, o entendimento quanto às diferentes deficiências. Através do que é objetivamente declarado, vamos abrindo caminhos que contribuam para um aprimoramento do "olhar" na percepção das necessidades de cada criança, na construção de propostas que valorizem e incentivem suas possibilidades, na proposição de adaptações significativas, na efetivação de uma participação que, além de considerar as particularidades referentes a cada criança, garanta que ela pertença de fato ao grupo.

No desenvolvimento das reflexões nos aproximamos do estudo de Heller (1992), destacando o que a autora denomina "momentos característicos" do comportamento e do pensamento, e valorizando sua importância na cotidianidade. A autora nos alerta à compreensão sobre os riscos de um cotidiano extremamente pragmático e pouco reflexivo, quando este leva a cristalizações e à perda da capacidade do indivíduo de se apropriar da realidade e de impor sobre ela sua marca. Estes conteúdos articulam-se com o compromisso diante das situações de inclusão. Que escolhas se faz? Que questionamentos são despertados? Que desconstruções histórica e culturalmente delineadas e assimiladas são necessárias?

Em meio às intercorrências diárias é necessário assumir riscos, evidenciar motivações particulares, apegarse a conhecimentos pré-estabelecidos. Na acelerada rotina, torna-se impossível um aprofundamento crítico diante de cada situação a ser oferecida ou vivenciada. O perigo, entretanto, reside na possibilidade destes mesmos elementos acabarem por se tornar armadilhas que impeçam o crescimento individual e o compromisso com o outro. Estas armadilhas são formadas quando as atitudes bastam por si mesmas, descaracterizando a capacidade reflexiva do indivíduo sobre seus atos e pensamentos e conduzindo a uma valorização única do particular, do conformismo, da facilidade em se manter tudo como está.

Assumir o desafio da inclusão significa enxergar a existência de conflitos e a necessidade deles serem trabalhados; exige o questionamento de atitudes; implica a revisão de práticas individuais e coletivas; requer a entrega pessoal na mobilização de mudanças que levem à ampliação de espaços participativos, a transformações na relação com a diferença, à descoberta de potencialidades, à busca de significados, à valorização das singularidades e das experiências pessoais. 
O desenvolvimento desta prática reflexiva, objetivo central na intervenção de um orientador como o terapeuta ocupacional, contribui para a conquista da efetivação de um novo lugar a ser oferecido à criança com deficiência: o lugar de aluno como sujeito que participa, escolhe e que espera a promoção de oportunidades que o auxiliem a ir em frente, a vencer desafios e a lidar com as dificuldades.

\section{CONSIDERAÇÕES FINAIS}

Espera-se poder contribuir para o aprofundamento das reflexões sobre inclusão no contexto escolar. Apontando para a necessidade de um desprendimento da condição de deficiência e da paralisação que o centramento único em seus aspectos promove, ressalta-se a importância de não haver um "fechamento" às sutilezas da observação, à inquietação saudável diante do "novo" e à disponibilidade no encontro com os desafios. Neste caminho, contribuise para uma ampliação na qualidade da transmissão de mensagens significativas, para a identificação de objetivos fundamentais e para o envolvimento real da criança com seu grupo e com o aprendizado que lhe é oferecido.

O Terapeuta Ocupacional, no compromisso com a efetivação de práticas de inclusão, tem o papel fundamental de auxiliar na identificação de alterações necessárias no cotidiano escolar, no desenvolvimento de uma postura reflexiva por parte dos diferentes profissionais e na transformação da maneira como se lida com a diversidade.

Sem desconsiderar as dificuldades macroestruturais, retoma-se aqui as possibilidades despertadas nos níveis locais, permeados pelas relações intersubjetivas, na proximidade concreta com as situações de sofrimento. Fazse fundamental a inovação no oferecimento de situações que promovam a ampliação de oportunidades, a valorização das trocas e o respeito às diferenças. Sem percursos que conduzam a estes caminhos, perde-se a oportunidade de se concretizar a digna participação de crianças que, por suas características, rompem com o que tradicionalmente se estipulou como pré-requisitos para as possibilidades de aprender.

SILVA, A. C. B. Inclusive education: contributions to the development of an ethical commitment in its implementation. Rev Ter Ocup Univ São Paulo, v. 23, n.2, p. 163-168, maio/ago. 2012.

\begin{abstract}
It is intended to contribute with the reflections concerning the school everyday, in regular education contexts in which there is the participation of children who present motor difficulties, associated to other difficulties or not. Dealing with, firstly, the school inclusion and the Occupational Therapy practice in the Children's Education context, it is aimed, secondly, a thoughts and actions analysis of the professionals involved with the inclusion, emphasizing the ethical commitment in the relations and in the development of a work which focuses on the disability condition unfastening the child's possibilities valorization the prejudice and superstitions overcoming and the guarantee that the teaching and learning processes take place significantly.
\end{abstract}

KEY WORDS: Child rearing; Occupational therapy; Education; Activities of daily leving; Educationof intellectually disabled; Learning.

\title{
REFERÊNCIAS
}

CASTRO, E. D.; et al. Análise de atividades: apontamentos para uma reflexão atual. In: CARLO, M. M. R. P; LUZO, M. C. de M. (Org). Terapia ocupacional: reabilitação física e contextos hospitalares. São Paulo: Roca, 2004.

CROCHÍK, J. L. Atitudes a respeito da educação inclusiva. Movimento, n. 7, 2003.

GOES, M. C. R.; LAPLANE, A. L. F. (Org.). Políticas e práticas de educação inclusiva. Campinas, SP: Autores Associados, 2004.

HELLER, A. O cotidiano e a historia. 4a. ed. Rio de Janeiro: Paz e Terra, 1992.
JERUSALINSKY, A.; et al. Psicanálise e desenvolvimento infantil: um enfoque transdisciplinar. Porto Alegre: Artes Médicas, 1988.

JURDI, A. P. S.; BRUNELLO, M. I. B.; HONDA, M. Terapia ocupacional e propostas de intervenção na rede pública de ensino. Rev.Ter.Ocup .Univ. São Paulo, v. 15, n. 1. p. 26-32, 2004.

ROCHA, E. F. Reabilitação de pessoas com deficiência. São Paulo: Roca, 2006.

ROCHA, E. F.; CASTIGLIONI, M. C.; VIEIRA, R.C. A inclusão da criança com deficiência na escola comum: reflexões sobre o papel da Terapia Ocupacional. Rev. Ter. Ocup. Univ. São Paulo, 
SILVA, A. C. B. Educação inclusiva: contribuições. Rev Ter. Ocup. Univ. São Paulo, v. 23, n. 2, p. 163-168, maio/ago. 2012.

v. $12, \mathrm{n} .1 / 3, \mathrm{p} .8-14,2001$.

ROCHA, E. F.; CASTIGLIONI, M. C. Reflexões sobre recursos tecnológicos: ajudas técnicas, tecnologia assistiva, tecnologia de assistência e tecnologia de apoio. Rev. Ter. Ocup. Univ. São Paulo, v. 16, n. 3, p. 97-104, 2005.

ROCHA, E. F.; LUIZ, A.; ZULIAN, M. A. R. Reflexões sobre as possíveis contribuições da terapia ocupacional nos processos de inclusão escolar. Rev. Ter. Ocup. Univ. São Paulo, v. 14, n. 2, p.72-78, 2003.

SAWAIA, B. B. (Org). As artimanhas da exclusão. Análise psicossocial e ética da desigualdade social. Petrópolis, RJ: Vozes, 1999.

Recebido para publicação: 20/05/2012

Aceito para publicação: 28/06/2012 